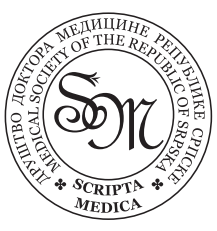

CASE REPORT

\title{
Functioning lipoadenoma of parathyroid gland
}

\begin{abstract}
We are describing a case of primary hyperparatyroidism due to liopadenoma of the parathyroid gland. After removal of the lipoadenoma, intraoperatively, there was an immediate decrease in the parathyroid hormone level. Awareness of this variant of parathyroid adenoma is important for surgical pathologists and surgeons to prevent misdiagnosis and patient management, given the morphologic overlap with parathyroid histology, especially if intraopeartive measurements of parathyroid hormone levels are not available.
\end{abstract}

\section{KEY WORDS}

Parathyroid adenoma, parathyroid lipoadenoma, hyperparathyroidism, parathyroid hormone

DOI: $10.7251 / S M D 1201038 C$

(Scr Med 2012;43:38-9)

\section{Akram Okleh, Carol Czapar, Marin Sekosan}

Department of Pathology

John H Stroger Jr. Hospital of Cook County, Chicago, Illinois, USA

\section{Correspodence}

Marin Sekosan, MD

John H Stroger Jr. Hospital of Cook

County, Chicago, IL 60612, USA

email: cchmsekosan@yahoo.com

Submitted: March 30, 2012

Accepted: May 2, 2012
A 78-year-old African American female with a past medical history of hypertension and diabetes mellitus type 2 was referred to the surgical service for surgical treatment of hyperparathyroidism. She had been essentially asymptomatic except, she was noted to have high calcium (9.5 $\mathrm{mg} / \mathrm{dL}$ ) and parathyroid hormone levels (preoperative PTH-112 ng/dL). Other pertinent laboratory data showed blood glucose- $94 \mathrm{mg} / \mathrm{dL}$, and creatinine- $0.9 \mathrm{mg} / \mathrm{dL}$.

The patient had undergone preoperative parathyroid scanning which demonstrated an abnormal uptake in the right inferior region consistent with parathyroid adenoma. Subsequently she underwent right inferior parathyroidectomy. Intraoperative parathyroid hormone levels, 5 minutes and 10 minutes post excision showed immediate decreased levels (Figure 1).

Intraoperative PTH Monitoring

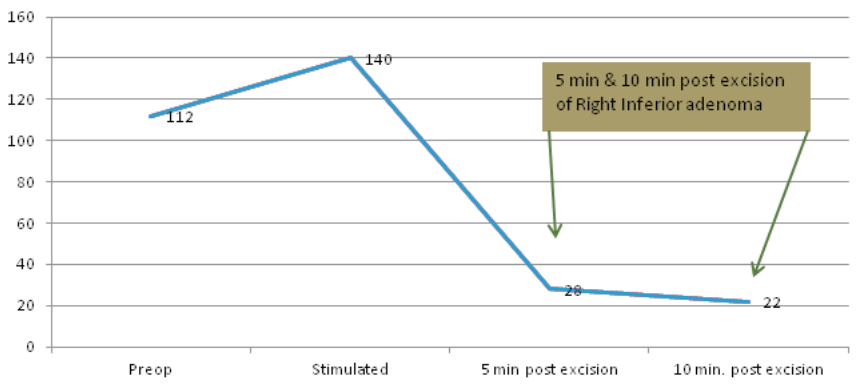

Figure 1: Intraoperative parathyroid hormone levels, 5 minutes and 10 minutes post excision showed immediate decreased levels of parathyroid hormone.

The specimens received by the pathology service consisted of a tan yellow parathyroid (labeled right inferior by the surgeon) with attached yellow fibroadipose tissue. The parathyroid gland was isolated; it measured $1.2 \times 0.7 \times 0.3$ $\mathrm{cm}$ and weighed 0.12 gram. The attached yellow adipose tissue measured $1 \times 0.9 \times 0.3 \mathrm{~cm}$. The specimen was inked and entirely submitted with sections fixed in $10 \%$ neutralbuffered formalin, processed, embedded in paraffin, sectioned, and then stained with hematoxylin-eosin.

Microscopically the parathyroid showed a lipoadenoma composed of mature adipose tissue (50\% of tumor), intermingled with mainly islands of parathyroid chief cells and

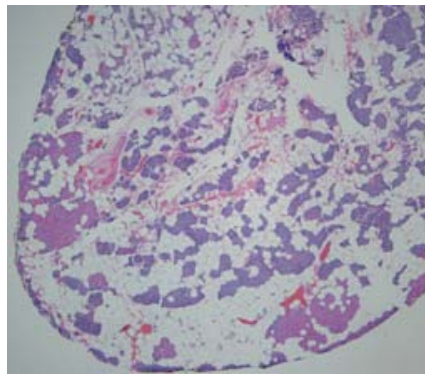

Figure 2: Parathyroid lipoadenoma; the tumor is circumscribed, $50 \%$ of tumor cell are mature adipocytes; intermingled are parathyroid cells forming islands (H\&E, power 50x)

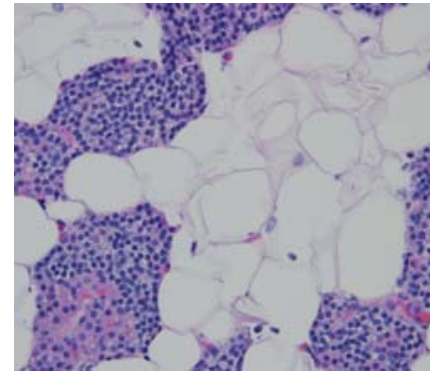

Figure 3: Lipoadenoma; the neoplastic parathyroid cells are mainly chief cells, few oxyphil cells are present (H\&E, power 500x) 
few islands of oxyphil cells (Figure $2 \& 3$ ). Mature adipose tissue containing benign involuted thymus tissue was also identified.

\section{Discussion}

Lipoadenoma is an unusual cause of primary hyperparathyroidism ${ }^{1}$; only 27 cases have been documented in the literature to date. According to Rosai et al, these tumors have been reported as parathyroid lipophyperplasia, parathyroid hamartoma and parathyroid adenoma with myxoid stroma. Lipoadenoma is a very rare morphologic variant of parathyroid adenoma showing intermingling of chief/oxyphil cells with abundant mature adipocytes, the latter comprising 20-90 percent of the tumor ${ }^{2}$. As in this case, the lesion sometimes overlaps with normal parathyroid tissue on microscopic examination ${ }^{3}$; however, the adenomatous nature of the lesion can be recognized by its circumscription and large size and at times presence of a rim of normal parathyroid gland $(1-15 \mathrm{~cm})^{3}$. At least half of the reported cases were functioning 4 . The differential diagnosis also includes parathyroid lipohyperplasia. However lipohyperplasia does not show a rim of normal parathyroid gland and usually involves all or most of the parathyroid glands $s^{5,6}$.

In summary parathyroid lipoadenoma is a rare cause of primary hyperparathyroidism and because of its unusual gross and morphologic findings, it can be misdiagnosed by surgeons and surgical pathologists ${ }^{4}$. Awareness of existence of this kind of parathyroid adenoma is important in preventing an intraoperative frozen section misdiagnosis resulting in surgical mismanagement, especially if intraoperative measurements of the parathyroid hormone levels are not available.

\section{Contributors}

$A O$ received and first reviewed the case. $C C$ is the attending and $M S$ the consultant on the case. AO, CC and MS contributed equally to the conception and writing of this article.

\section{Conflicts of interest}

We declare that we have no conflicts of interest.

\section{References}

1. Ducatman BS, Wilkerson SY, Brown JA. Functioning parathyroid lipoadenoma. Report of a case diagnosed by intraoperative touch preparations. Arch Pathol Lab Med 1986:645-7.

2. Bansal R, Trivedi P, Parikh B, et al. Lipoadenoma of the parathyroid gland-A rare cause of hyperparathyroidism. Gulf $\mathrm{J}$ Oncology 2012:63-5.

3. Chan JKC. The parathyroid gland. In: Flrtcher CDM, ed. Diagnostic Histopathology of Tumors, Third edition. Chrchill Lingstone 2007:1086.

4. Rosai J. Parathyroid glands. In: Rosai J, ed. Rosai and Ackerman's Surgical Pathology, Ninth edition. Edinburgh, London New York St Lois Toronto; Mosb; 2004:599.

5. Straus DH, Kaplan EL, Nishiyama RH et al. Five cases of parathyroid lipohyperplasia. Surgery 1983; 94 (6): 901-5.

6. Seethala RR, Oglivie JB, Carty SE et al. Parathyroid Lipoadnomas and liophyperplasias Clinicopathologic Correlations. Am J Surg Pathol 2008; 1854-1867. 